\title{
Optimization of cultural parameters for the production of antimicrobial compound from Lactobacillus fermentum (MTCC No. 1745)
}

\begin{abstract}
To improve the productivity of antibacterial compounds of Lactobacillus fermentum by optimizing its nutrient and physical factors and screened for its antimicrobial activity by agar well diffusion method. In order to improve its efficiency, the effects of medium components carbon and nitrogen sources, temperature, $\mathrm{pH}$, agitation, incubation time, were optimized and its productivity was determined by agar well diffusion method against four bacterial strains obtained from MCC, Pune, India namely E.coli, Bacillus subtilis, Staphylococcus aureus, Psudomonas aeruginosa. The bacterial inhibition rate was more in the optimized medium composition $(\mathrm{g} / 100 \mathrm{~mL})$, containing dextrose 3.0 , tryptone 1.5 and incubation time for $72 \mathrm{hrs}$, temperature $36 \pm 2{ }^{\circ} \mathrm{C}$ and $\mathrm{pH}$ 7. Compared to basal medium the optimized medium shown about 1.2 fold increased in the zone of inhibition by Lactobacillus fermentum. The results from this study confirmed that the antibacterial substances produced by Lactobacillus fermentum were found to be more effective after its optimization.
\end{abstract}

Volume 4 Issue 5 - 2017

\author{
VSSL Prasad Talluri,' Sri Santhi Lanka ${ }^{2}$ \\ 'Department of Biotechnology, University of Gondar, Ethiopia \\ ${ }^{2}$ Department of Biotechnology, GITAM University, India \\ Correspondence: VSSL Prasad Talluri,Assistant Professor, \\ Department of Biotechnology, College of Natural and \\ Computational Science, University of Gondar, Gondar, Ethiopia, \\ Email talluri.chowdary526@gmail.com
}

Received: January 18, 2017 | Published: May 08, 2017

Keywords: lactobacillus fermentum, zone of inhibition, optimization, antimicrobial compounds, lactic acid bacteria

\section{Introduction}

Lactic acid bacteria (LAB) are economically important since they used in food and feed fermentation. They produce different types of substrates with the antimicrobial properties which can be used as bio preservatives $^{1}$ Lactobacillus are gram positive bacteria fitting within the general definition of LAB. LAB has been used in the production of a variety of dairy, vegetables and meat fermented foods for many centuries. Lactobacillus are used in probiotics improving the microbial balance of intestine or assay beneficial agent in the treatment of gastro enteritis in humans and animals. ${ }^{2}$ In addition to the contribution to the typical sensory characteristics of these foods, ${ }^{3} \mathrm{LAB}$ exert a strong antimicrobial activity against many microorganisms, as a result of the production of hydrogen peroxide, organic acids, inhibitory enzymes, antimicrobial compounds and bacteriocins. ${ }^{4}$ Production of antimicrobial compounds by an Lactobacillus fermentum depends on many parameters like nutrients, salt concentration, $\mathrm{pH}$ and temperature. In fact, the composition of culture medium closely associated with the metabolic capacities of the producing strain and significantly influences the biosynthesis of secondary metabolites. ${ }^{5}$ The concept of medium optimization for secondary metabolites production involves the exploitation of medium components and cultural condition to obtain the desired product in a cost effective manner.

In the present investigation an attempt has been made to investigate the effect of different nutrients and cultural conditions for the maximum production of Zone of inhibition by Lactobacillus fermentum.

\section{Materials and methods}

\section{Materials}

MRS broth, yeast extract, Tryptone, lactose, nutrient broth, malt extract, dextrose and galactose were procured from Himedia, Mumbai,
India. Maltose, beef extract, Sucrose, nutrient agar, Xylose, fructose, from Merck, India. All chemicals used were of analytical grade.

\section{Methods}

The isolate Lactobacillus fermentum (MTCC No. 1745) used in this study was procured from MTCC (Microbial type culture collection), Chandigarh, India.

\section{Test organisms used in the study}

E.coli, Bacillus subtilis, Psudomonas aeruginosa, Staphylococcus aureus, were obtained from MCC, Pune. The cultures obtained were in the form of lyophilized powders in sealed vials. The cultures were revived in Nutrient broth and stored in agar slants for further study.

\section{Effect of different carbon sources}

Lactobacillus fermentum was inoculated in the basal media and kept in incubator shaker at optimized speed and temperature for 36 hours. Various carbon sources used in the medium were arabinose, fructose, dextrose, galactose, glucose, lactose, maltose, mannose and sucrose at a final concentration of $1 \%$. A flask without any carbon source was kept as a control.

\section{Determination of optimum concentration of best carbon source}

Among different carbon sources used, the carbohydrate which supported the maximum growth of Lactobacillus fermentum and production of Zone of inhibition was further optimized by changing its concentration from $1 \%$ to $6 \%$ and determined the optimum concentration of the best carbon source.

\section{Effect of different nitrogen sources}

The growth and production of Zone of inhibition was controlled 
by using different nitrogen sources like L-asparagine, tyrosine, casein, beef extract, peptone, soybean meal, tryptone and yeast extract at a final concentration of $1 \%$.

\section{Determination of optimum concentration of best nitrogen source}

The maximum production of Zone of inhibition shown by nitrogen source was further optimized by altering its concentration from $0.5 \%$ to $3.0 \%$, to determine the optimum concentration.

\section{Effect of $\mathrm{pH}$}

To evaluate the effect of $\mathrm{pH}$ on growth and zone of inhibition was determined by changing the $\mathrm{pH}$ (5.0 to 9.0$)$ by adjusting to required value by addition of $1 \mathrm{~N} \mathrm{HCl}$ or $1 \mathrm{~N} \mathrm{NaOH}$ of the optimized media containing best carbon and nitrogen source.

\section{Effect of temperature}

The optimized media containing best nitrogen, carbon sources at optimum $\mathrm{pH}$ was incubated at various temperatures ranging from $20^{\circ} \mathrm{C}$ to $50^{\circ} \mathrm{C}$, to determine the optimum temperature required for maximum growth and production of Secondary metabolite.

\section{Effect of incubation period}

The optimum incubation period required for the growth and production of Zone of inhibition was determined by incubating the optimized media with best carbon, nitrogen and amino acid sources at optimum $\mathrm{pH}$ and temperature at different incubation periods $(12 \mathrm{~h}$ to $96 \mathrm{~h})$.

\section{Statistical analysis}

The results analyzed in this study were the mean or SD (Standard Deviation) of three independent experiments. The data was statistically analyzed by one way ANOVA and the means were assessed by DMRT (Dunken Multiple Range Test) at $0.5 \%$ level of significance.

\section{Results and discussion}

\section{Effect of different carbon sources}

Maximum zone of inhibition shown by Lactobacillus fermentum was observed with dextrose as a carbon source (Figure 1). Whereas minimum zone of inhibition was observed with lactose.

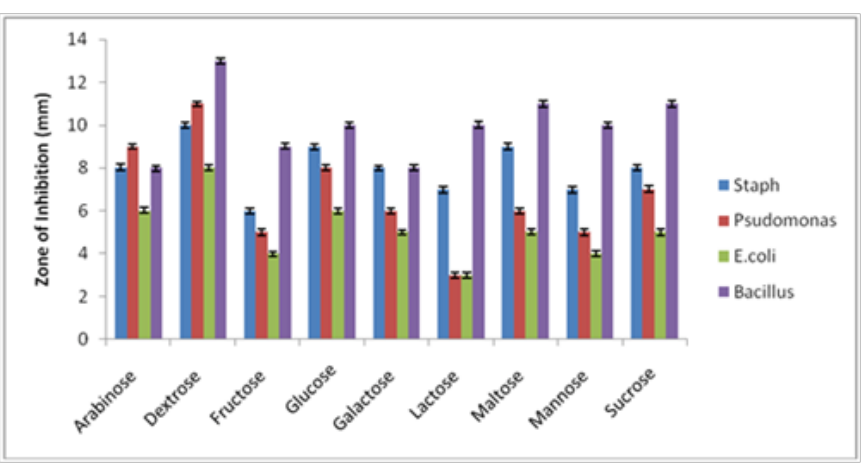

Figure I Effect of carbon source on the growth of Lactobacillus fermentum and zone of inhibition.

\section{Determination of optimum concentration of best carbon source}

As shown in the Figure 2, there is an increase in the zone of inhibition production at $3 \mathrm{~g}$ of dextrose.

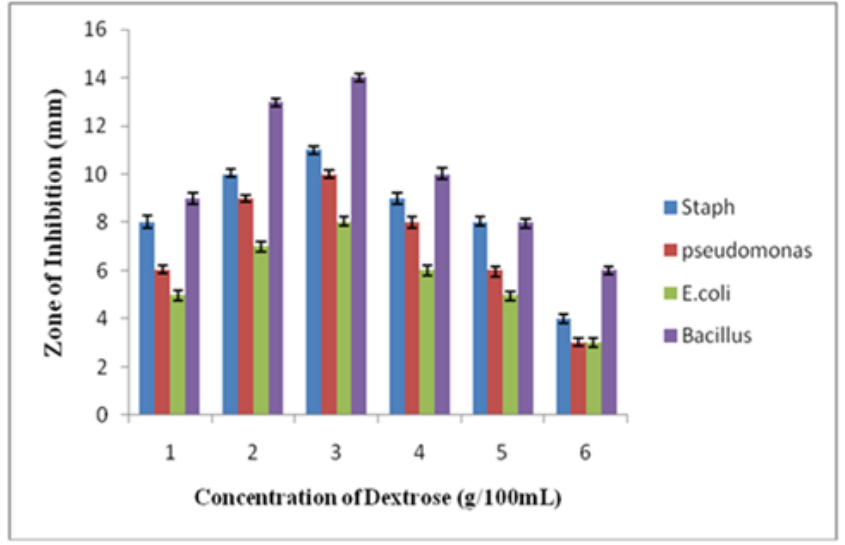

Figure 2 Determination of optimum concentration of best carbon source.

\section{Effect of different nitrogen sources on of zone of} inhibition

Among eight different nitrogen sources used, maximum zone of inhibition was observed with tryptone followed by beef extract and soybean meal (Figure 3). Low Zone of inhibition production was observed in the medium containing casein.

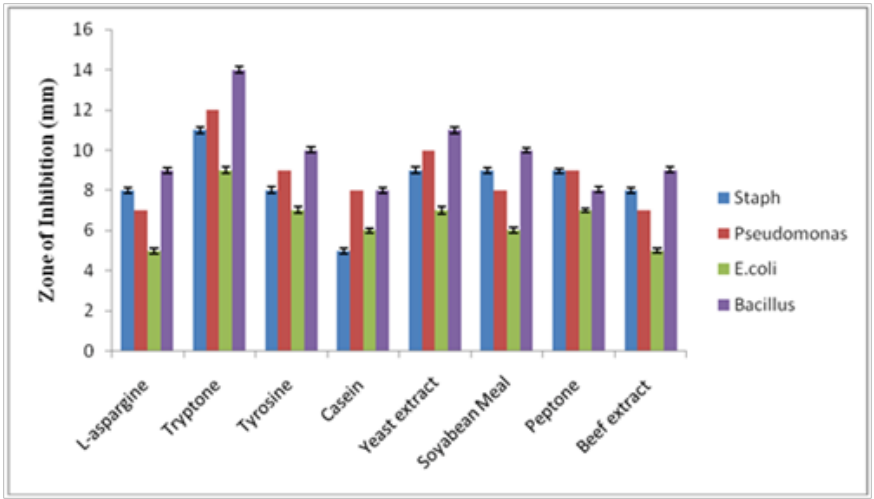

Figure 3 Effect of Nitrogen source on Lactobacillus fermentum.

\section{Determination of optimum concentration of best nitrogen source}

As shown in Figure 4, there is a continuous increase in the growth of Lactobacillus fermentum and zone of inhibition production from 0.5 to $3 \mathrm{~g}$ of trptone. However, further increase in the tryptone concentration showed a gradual decrease in Zone of inhibition.

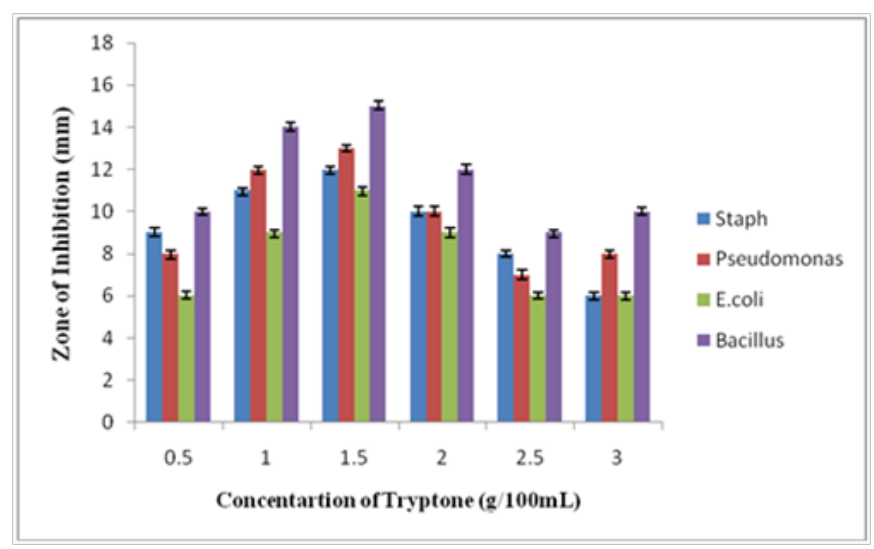

Figure 4 Effect of tryptone on growth and zone of inhibition. 
Effect of $\mathrm{pH}$ on growth of Lactobacillus fermentum and of zone of inhibition

The zone of inhibition was observed at $\mathrm{pH} 6.0$ and beyond this there is a sudden decrease in zone of inhibition at $\mathrm{pH} 8.0$ (Figure 5).

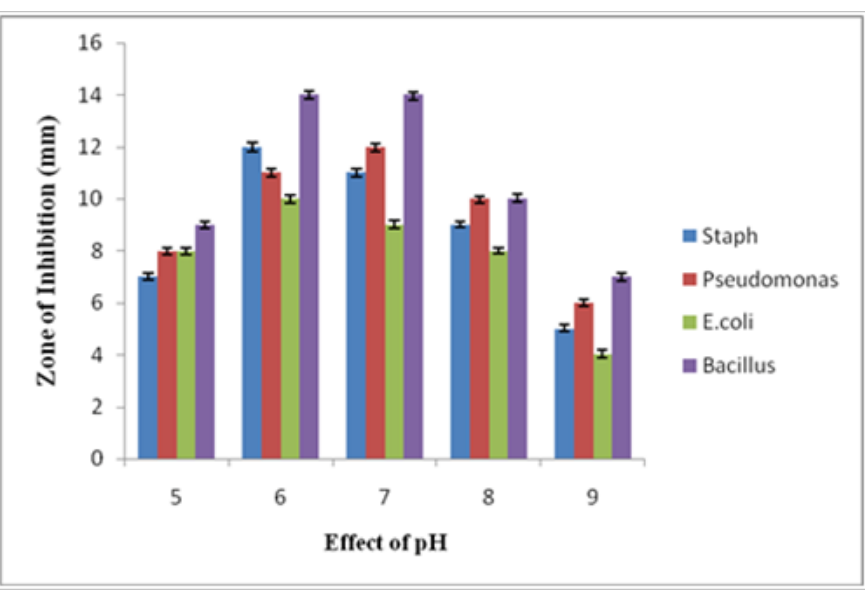

Figure 5 Effect of $\mathrm{pH}$ on growth and Zone of inhibition production.

\section{Effect of on temperature Lactobacillus fermentum and zone of inhibition}

Figure 5, shows the optimum zone of inhibition at $35^{\circ} \mathrm{C}$ and beyond optimal temperature, zone of inhibition was less.

\section{Effect of incubation time on Lactobacillus fermentum and zone of inhibition}

There was a sharp increase in the growth of Lactobacillus fermentum and Zone of inhibition from 48hours of incubation and gradually increased up to $72 \mathrm{~h}$ of incubation (Figure 6).

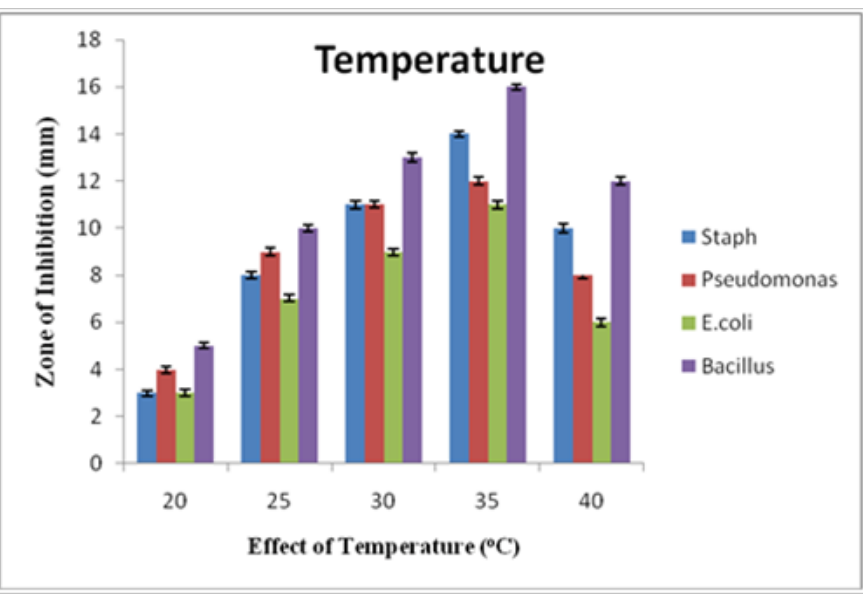

Figure 6 Effect of temperature on growth and Zone of inhibition production

Mushood et al., ${ }^{6}$ reported optimization of temperature and $\mathrm{pH}$ conditions for the production of secondary metabolite using Lactobacillus faecium B3L 3 at $\mathrm{pH} 8$ and $37^{\circ} \mathrm{C}$. Ouardy et al., ${ }^{7}$ has reported $2 \%$ tryptone and $\mathrm{pH} 6.5$ has increases the antimicrobial activity compared to control in Lactobacillus durans E204.

\section{Conclusion}

Based on the above optimized studies, the composition of the nutrient medium and physical parameters required for the optimum growth and zone of inhibition by Lactobacillus fermentum were presented in Table 1. When compared to basal medium the optimized medium showed about 1.2 fold increased in the production of Zone of inhibition by Lactobacillus fermentum (Figure $7 \& 8$ ). Similar reports were observed by Marine bacteria Lactobacillus with a 1.6 fold increase. ${ }^{8,9}$

Table I Optimized production medium and culture conditions for Lactobacillus fermentum

\begin{tabular}{ll}
\hline $\begin{array}{l}\text { Composition of optimized production medium } \\
\text { and cultural conditions }\end{array}$ & $\mathbf{( g / 1 0 0 \mathrm { mL } )}$ \\
\hline Dextrose & 3 \\
Tryotone & 1.5 \\
Yeast extract & 0.5 \\
Sodium acetate & 0.5 \\
Di-potassium phosphate & 0.3 \\
pH & 6.5 \\
Temperature & $36^{\circ} \mathrm{C}$ \\
Aeration & $160 \mathrm{rpm}$ \\
Incubation time period & $76 \mathrm{~h}$ \\
\hline
\end{tabular}

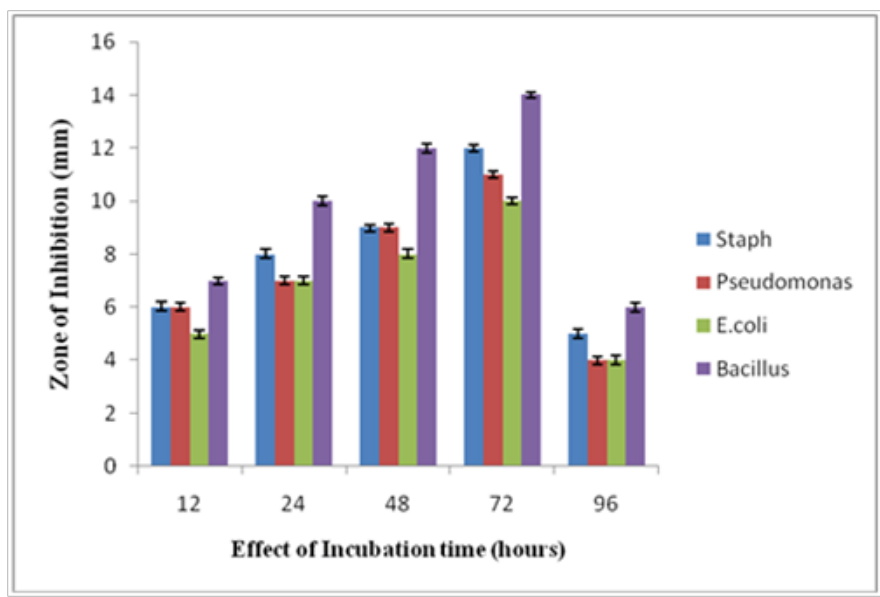

Figure 7 Effect of Incubation time on growth and zone of inhibition production.

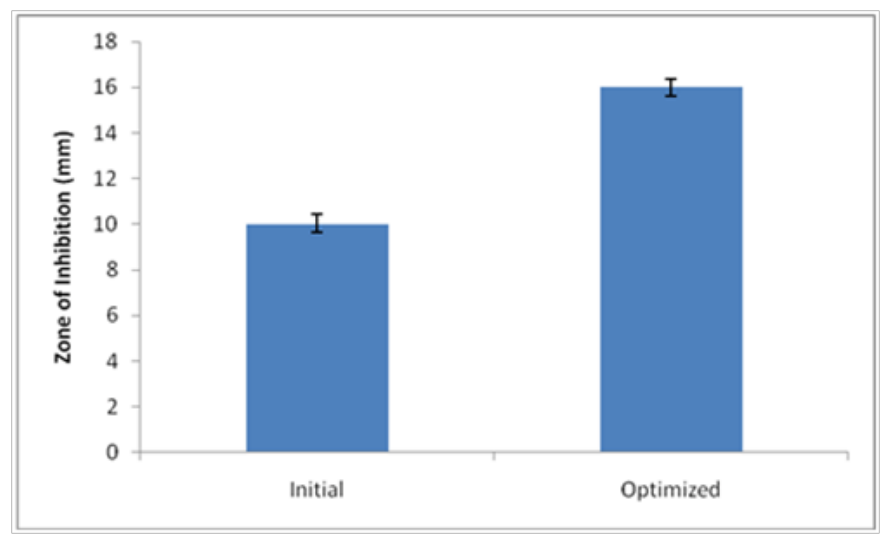

Figure 8 Zone of inhibition production by basal and optimized media. 


\section{Acknowledgements}

The authors are thankful to the management of GITAM University for providing necessary research facilities to carry out this work.

\section{Conflict of interest}

The author declares no conflict of interest.

\section{References}

1. Centeno JA, Menéndez S, Rodríguez-Otero JL. Main microbial flora present as natural starters in Cebreiro raw cow's-milk cheese (Northwest Spain). Int J Food Microbiol. 1996;33(2-3):307-313.

2. Stiles ME, Holzapfel WH. Lactic acid bacteria of foods and their current taxonomy. Int J Food Microbiol. 1997;36(1):1-29.

3. Fox PF, Wallace JM. Formation of flavour compounds in cheese. $A d v$ Appl Microbio. 1997;45:17-85.

4. Piard JC, Desmazeaud M. Inhibiting factors produced by lactic acid bacteria. 2. Bacteriocins and other antibacterial substances. Lait. 1992;71(2):113-142.
5. Vilches C, Méndez C, Hardisson C, et al. Biosynthesis of oleandomycin by Streptomyces antibioticus: influence of nutritional conditions and development of resistance. J Gen Microbiol. 1990;136(8):1447-1454.

6. MoshoodAY, TengkuHaziyamin Abdul TAH. Optimization of temperature and $\mathrm{pH}$ forthe growth and bacteriocin production of Lactobacillus faecium B3L3. IOSR Journal of Pharmacy. 2012;2(6):49-59.

7. Ouardy Khay, Mustapha Ouhsassi, Abdeltif El Harsal, et al. Optimization of bacteriocin-like production by Lactobacillus Durans E204 Isolated From Camel Milk of Morocco. Current Research in Microbiology and Biotechnology. 2013;1(4):155-159.

8. Murray PR, Baroon EJ, Pfaller MA, et al. Manual of clinical microbiology. 6th ed. USA: American Society for Microbiology; 1995.

9. Vandana Bali, Manab B Bera, Parmjit S Panesar. Utilization of agro-industrial byproducts for bacteriocin production using newly isolated Lactobacillus faecium BS13. International Journal of Biological, Veterinary, Agricultural and Food Engineering. 2014;8(6):1-5. 